\title{
Ocorrência de enteropatia proliferativa em suínos abatidos no Paraná*
}

\section{Occurrence of proliferative enteropathy in swine slaughtered on the Paraná state}

\author{
Milton Alves Junior," Ana Paula Frederico Rodrigues Loureiro Bracarense, ${ }^{\star \star \star}$ Antonio Carlos Faria dos Reis, ${ }^{\star \star \star}$ \\ Amauri Alcindo Alfiere, ${ }^{\star \star \star}$ Marina Tie Shimada ${ }^{\star \star \star \star}$
}

\begin{abstract}
Resumo
A enteropatia proliferativa dos suínos agrupa diversas patologias com aspectos macroscópicos diferentes: adenomatose intestinal $_{s}$ ileíte regional, enterite necrótica e enteropatia proliferativa hemorrágica. Estudou-se a ocorrência de enteropatia proliferativa em suínos abatidos no estado do Paraná, onde foram colhidas amostras de duodeno, jejuno, íleo, cólon e linfonodo mesentérico de 389 animais. As amostras foram obtidas em três frigoríficos do estado, sendo um na região Norte, um na região Sudeste e um na região Sudoeste. Do total de animais, 12 foram positivos, o que representa $3,08 \%$. $A$ única forma da doença encontrada foi a adenomatose intestinal. O diagnóstico foi caracterizado pelas alterações histopatológicas provocadas pelo agente no trato intestinal afetado.
\end{abstract}

Palavras-chave: ileíte; enteropatia proliferativa; enterite proliferativa; complexo adenomatose; suíno.

\begin{abstract}
The proliferative enteropathy of the swine contains several pathologies with different macroscopic aspects: intestinal adenomatosis, regional ileitis, necrotic enteritis and haemorragic proliferative enteropathy. It was studied the occurrence of the proliferative enteropathy in swine slaughtered on the state of Paraná, where were taken duodenum, jejune, ileum, colon and mesenteric linfonodes samples of 389 animals. The samples were obtained in slaughter-house of the State being one in the North area, one in the Southeast area and one in the Southwest area. Of the total of animals, 12 were positive, what represents $3,08 \%$. The unique form found, was the intestinal adenomatosis form. The diagnosis was characterized by the histopathological alterations induced by the agent in the affected intestinal tract.
\end{abstract}

Keywords: ileitis; proliferative enteropathy; proliferative enteritis; adenomatosis complex; swine.

\section{Introdução}

A enteropatia proliferativa dos suínos (EPS) é atualmente uma das enteropatias mais diagnosticadas em suínos de terminação (McOrist e Lawson, 1993). Clinicamente manifesta-se como uma redução no ganho de peso na fase de crescimento (McOrist et al., 1989) ou um quadro intestinal hemorrágico em animais de terminação (Lawson e McOrist, 1993). A EPS agrupa diversas patologias com aspectos macroscópicos e microscópicos diferentes que são conhecidas como complexo adenomatose intestinal dos suínos. Dentro deste complexo encontram-se adenomatose intestinal, ileíte regional, enterite necrótica e enteropatia hemorrágica proliferativa.

A ocorrência da EPS em suinos destinados ao abate é relatada por diversos autores, sendo a incidência bastante variável
- de $0,7 \%$ a $1,63 \%$ até $40 \%$ em outros trabalhos (Pointon, 1989; Connor, 1991). Na Holanda, em 1995, a incidência de adenomatose intestinal em suínos foi de 2,5\% (Ridder et al., 1996). Mercy e Brennan (1988) relatam que, na Austrália, $15 \%$ do rebanho está afetado. No Reino Unido estima-se que meio milhão de suínos sejam afetados anualmente pela doença (McOrist et al., 1997). Em Taiwan a prevalência da doença varia de $15,4 \%$ a $46,7 \%$ (Chang et al., 1997) e na Polônia, entre 10 a 20\% (Pejsak et al., 1997).

Existem no Brasil seis registros de EPS nas formas: enteropatia proliferativa hemorrágica, ileíte regional e adenomatose intestinal, nos estados do Rio Grande do Sul, Santa Catarina, São Paulo, Rio de Janeiro e Minas Gerais (Barcellos et al., 1992). Também foi diagnosticada EPS no estado de São Paulo (Baccaro et al., 1997). No estado do

\footnotetext{
* Apoio financeiro - CNPq.

** Universidade de Marília, Hospital Veterinário, setor de Patologia Animal, CEP 17525-902, Marília, SP.

*** Universidade Estadual de Londrina, caixa postal 6001, Depto. Med.Vet. Preventiva, CEP 86051-990, Londrina, PR. e-mail- anapaula@ uel.br. **** Bolsista PIBIC/CNPq.
} 
Paraná não há relatos sobre EPS ou levantamentos sobre a ocorrência dessa patologia. $O$ objetivo do presente estudo foi conhecer a ocorrência da doença no estado do Paraná, classificar os tipos de lesões e detectar o agente etiológico através da técnica de Warthin-Starry.

\section{Material e métodos}

Para determinação do número de amostras utilizou-se o programa estatístico EPI-INFO versão 6,04 (CDC, Atlanta-EUA). Para este cálculo, considerou-se em 2.050.000 animais a população de suínos abatidos anualmente no estado do Paraná e um nível de confiança de $95 \%$. As amostras foram colhidas de forma aleatória em frigoríficos com Serviço de Inspeção Federal (SIF) representativos da região Norte, Sudeste e Sudoeste do estado do Paraná, sendo que de cada lote de animais abatidos, cinco a dez animais eram trabalhados. Analisou-se a origem (municipios) dos animais abatidos através de dados obtidos junto ao SIF. As amostras foram colhidas em um período de seis meses.

Foram colhidas 389 amostras de tecidos de suínos. Estas amostras eram fragmentos de duodeno, jejuno, íleo, cólon e linfonodos mesentéricos. Os fragmentos mediam aproximadamente $10 \mathrm{~cm}$ e foram fixados intraluminalmente com formol tamponado a 10\%, sendo então submetidos a desidratação em soluções crescentes de álcoois, diafanização em xilol e inclusão em parafina. Os cortes com $5 \mathrm{~mm}$ de espessura foram corados pelo método de hematoxilina-eosina (HE). Nas amostras que apresentaram características histológicas de EPS realizou-se a impregnação pela prata através do método de Warthin-Starry (WS).

Foram colhidas fezes para exames parasitológicos através do método de Willis e para detecção de rotavírus. Neste, o método utilizado foi extração do RNA pela técnica de fenol-clorofórmio/ álcool isoanílico e análise pela técnica de eletroforese em gel de poliacrilamida. Estes exames foram realizados em todas as amostras com características histológicas de EPS e em 45 animais que não apresentaram lesões.

Os resultados obtidos foram submetidos à análise estatística através do teste de Qui-quadrado $\left(\chi^{2}\right)$, para um $\alpha=0,05$.

\section{Resultados}

Do total de 389 amostras de tecidos analisadas pela histopatologia, 12 animais apresentaram alterações características de EPS, o que representa $3,08 \%$ de casos positivos (Figura 1).

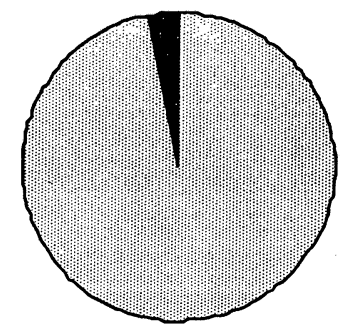

GAmos tras negativas $-96.92 \%$ Amos tras positivas - $3,08 \%$

Figura 1: Ocorrência de enteropatia proliferativa em suínos no estado do Paraná.
A distribuição do número de amostras colhidas e positivas por região está demonstrada na Tabela 1, sendo que a diferença numérica de amostras positivas entre as regiões Norte, Sudeste e Sudoeste não foi estatisticamente significante.

Em relação à origem das amostras colhidas, constatou-se que 46 municípios foram abrangidos neste estudo, sendo que em oito foram observadas alterações histológicas compatíveis com EPS. A análise estatística demonstrou não haver significância entre o número de municípios com amostras positivas nas diferentes regiões do estado (Tabela 1).

Tabela 1: Distribuição do número de municípios e amostras com ocorrência de enteropatia proliferativa em suínos nas regiões do estado do Paraná.

\begin{tabular}{ccccc}
\hline REGIÃO & $\begin{array}{c}\text { N.9 } \\
\text { Municipios* }\end{array}$ & $\begin{array}{c}\text { N.9 Municípios } \\
\text { Positivos* }\end{array}$ & $\begin{array}{c}\text { N.9 } \\
\text { Amostras }^{* *}\end{array}$ & $\begin{array}{c}\text { N.9 Amostras } \\
\text { Positivas }^{* *}\end{array}$ \\
\hline NORTE & 08 & 02 & 75 & 02 \\
SUDESTE & 11 & 01 & 133 & 01 \\
SUDOESTE & 27 & 05 & 181 & 09 \\
\hline TOTAL & 46 & 08 & 389 & 12 \\
\hline
\end{tabular}

${ }^{*} \chi^{2}=0,87 \mathrm{p}=0,646 ;{ }^{* \star} \chi^{2}=0,62 \quad \mathrm{p}=0,099$.

O percentual de amostras positivas nas diferentes áreas do estado está demonstrado na Figura 2.

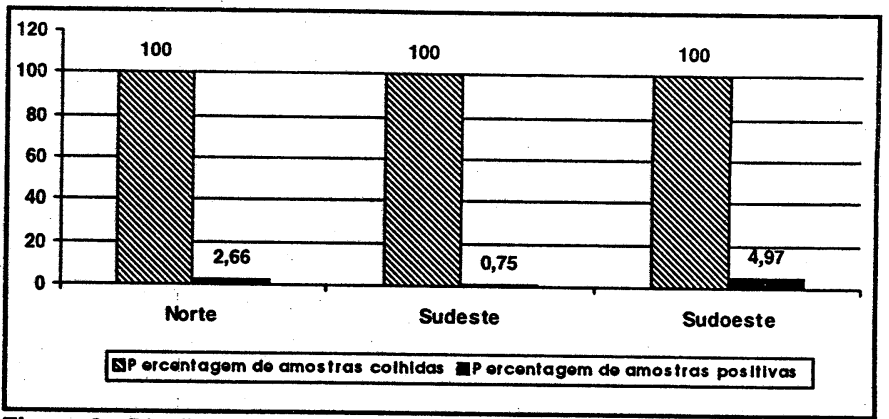

Figura 2: Distribuição percentual de amostras positivas para enteropatia proliferativa em suínos nas diferentes regiōes do estado do Paraná

O exame virológico não revelou rotavírus em nenhum dos animais analisados. No exame parasitológico dos animais com enteropatia proliferativa constatou-se em 1 , a presença de ovos de estrongilídeos ( + ) e, em outro, a presença de ovos de ascarídeos (++).

Foram considerados casos positivos de EPS os animais com os seguintes achados histopatológicos: hiperplasia de mucosa, presença de criptas intestinais alongadas, ramificadas (Figura 3 ) e revestidas por epitélio imaturo pseudoestratificado colunar. As células apresentavam citoplasma levemente eosinófilo, núcleo aumentado de volume, alongado e com um ou mais nucléolos.

Constatou-se elevação do índice mitótico e diminuição do número de células caliciformes. A lâmina própria mostrou congestão e moderado infiltrado inflamatório constituído por células mononucleares e eosinófilos (Figura 4). Observaramse centros germinativos ativos nas placas de Peyer. A submucosa apresentou congestão. Não foram observadas alterações na camada muscular. 


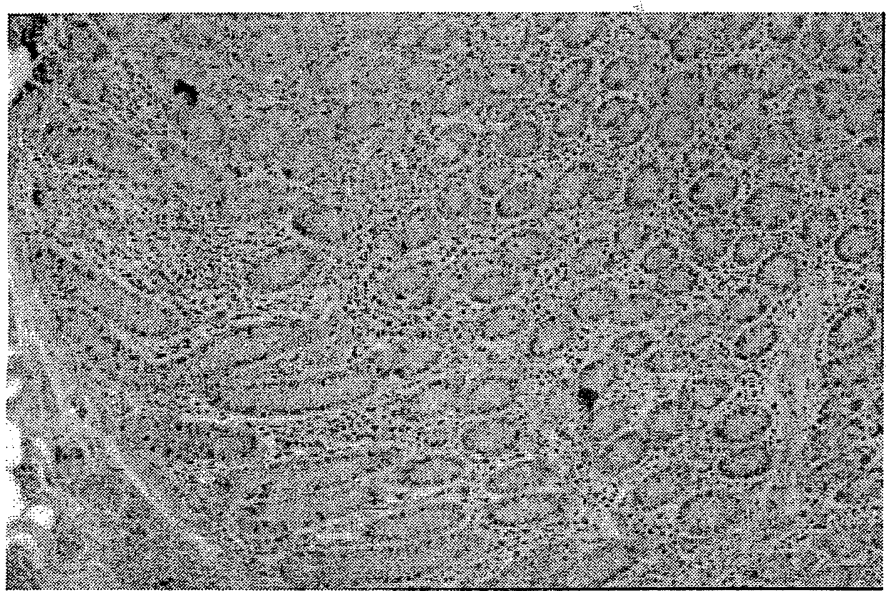

Figura 3: Hiperplasia de criptas intestinais na região de íleo de suíno com enteropatia proliferativa. H.E. Obj. $5 x$.

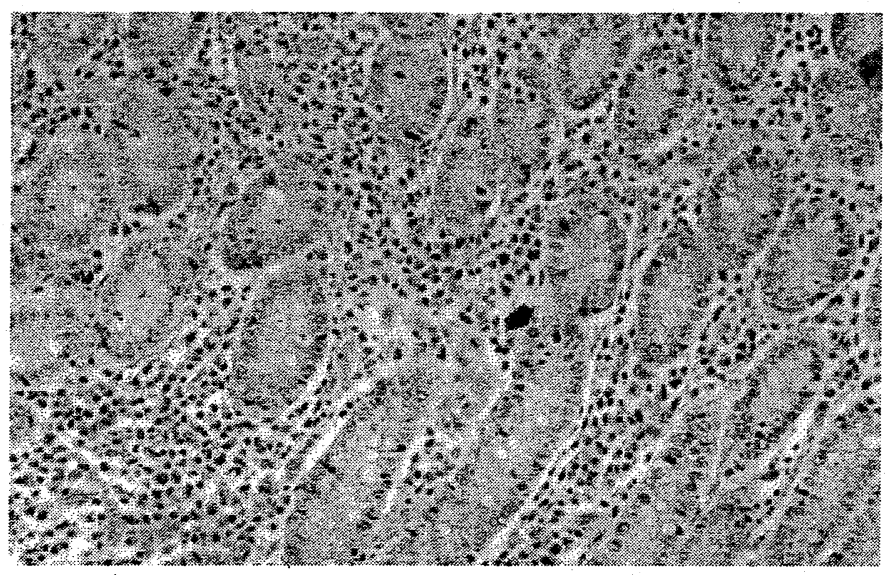

Figura 4: Aumento do número de figuras de mitose (seta) no epitélio das criptas, diminuição do número de células caliciformes e infiltrado inflamatório mononuclear (seta dupla) em íleo de suino com enteropatia proliferativa. H.E. Obj. $20 x$.

Os linfonodos mesentéricos apresentaram acentuada ativação dos folículos linfóides que abrangia toda a região cortical. Nos demais tecidos não foram observadas alterações dignas de nota.

As alterações microscópicas nos 12 animais restringiramse ao íleo, sendo classificadas dentro do complexo enteropatia proliferativa dos suínos na forma de adenomatose intestinal. No método de Warthin-Starry não foi possível detectar o agente bacteriano no citoplasma apical das células intestinais.

Nos demais animais não houve hiperplasia da mucosa; no entanto, constatou-se um infiltrado inflamatório eosinofílico e mononuclear de discreta intensidade, ativação de placas de Peyer e de folículos linfóides nos linfonodos mesentéricos.

\section{Discussão e conclusão}

Considerando que as amostras obtidas neste trabalho eram de animais abatidos em frigoríficos, sem sinais clínicos de doença, a ocorrência de $3,08 \%$ de EPS observada no estado do Paraná está de acordo com relatos de Pointon (1989), Connor (1991) e Ridder et al. (1996). Essa ocorrência pode estar subestimada, já que alguns autores consideram que, na maioria das vezes, há uma recuperação espontânea dos animais (McOrist e Lawson, 1993).

Os animais avaliados neste estudo não apresentavam sinais clínicos. A anorexia transitória é descrita como característica da adenomatose intestinal, sendo que a diarréia nem sempre (McOrist, 1996). Nestes casos, a forma de detecção da doença seria através do registro preciso do ganho de peso do animal durante a fase de crescimento.

McOrist (1996) relata que a adenomatose intestinal ocorre nos últimos $50 \mathrm{~cm}$ do intestino delgado e no terço proximal do cólon. Neste trabalho, observamos que as lesões microscópicas restringiram-se à porção terminal de íleo.

As lesões microscópicas observadas em 12 animais estão de acordo com as descritas por Mores et al. (1985); Barcellos et al. (1992) e McOrist (1996), caracterizando a doença na forma de adenomatose intestinal. De acordo com Ward e Winkelman (1990), as lesões microscópicas definem a etiologia da doença. Os fragmentos de íleo dos animais afetados apresentaram proliferação celular e imaturidade do epitélio intestinal; no entanto, observou-se diminuição do número de células caliciformes e não ausência, como relatam Barcellos et al. (1992) e McOrist (1996). Este fato pode ser decorrência de recuperação da doença, como citam McOrist e Lawson (1993).

Hiperplasia e hipertrofia de placas de Peyer e aumento da atividade mitótica dos centros germinativos de linfonodos foram observados por Alderton et al. (1992) em suínos inoculados experimentalmente. Nos animais avaliados neste estudo, a ativação das placas de Peyer e de linfonodos não ocorreu apenas nos casos positivos, mas em todos os suinos.

O método de impregnação pela prata não foi eficiente em demonstrar o agente nas células intestinais de animais com lesões microscópicas na forma de adenomatose intestinal Baccaro et al. (1997) citam que este método nem sempre é eficiente, devido à espessura do corte, que pode não representar o segmento contendo o agente. Jensen et al. (1997) relatam que os casos de enteropatia proliferativa sem sinais clínicos e alterações macroscópicas devem ser avaliados através da técnica de PCR e imuno-histoquímica para determinação do agente.

Neff (1993), Mansfield e Urban (1996) relatam que, além da Lawsonia intracellularis, outros fatores como o parasitismo intestinal e a presença de rotavírus podem favorecer o estabelecimento de enteropatia proliferativa em suínos. Os dados obtidos neste trabalho não confirmaram este fato, visto que em nenhum dos animais com adenomatose intestinal foi detectado o rotavírus e apenas um pequeno número apresentou infestação parasitária.

A vigilância em frigoríficos é utilizada para estimar a presença e o possível impacto dessa doença. A partir destes dados espera-se conhecer o reflexo nos animais vivos e a perda econômica na produção. Neste trabalho, concluímos que a vigilância em animais destinados ao abate mostrouse eficiente para determinar a ocorrência de EPS no estado do Paraná, sendo que o exame histopatológico serviu como método de triagem, indicando a ocorrência de lesões características. No entanto, a identificação do agente 
revelou-se insatisfatória nesta amostragem, necessitando de métodos mais específicos.

O número de animais com lesões características da doença não apresentou diferença estatística significante entre as diferentes regiões e quanto aos municípios envolvidos. Estes dados indicam que o número de amostras colhidas por região foi representativo e que a doença apresenta-se uniformemente disseminada pelo estado.

\section{Referências bibliográficas}

ALDERTON, M.R., BORLAND, R., COLOE, P.J. Experimental reproduction of porcine proliferative enteritis. J. Comp. Path., v. 106, p. 159167, 1992.

BACCARO, M.R., MORENO, A.M., COUTINHO, L.L. Entente proliferativa suína: aspectos histopatológicos e diagnóstico através da reação em cadeia da polimerase. ENCONTRO NACIONAL DEPATOLOGIA VETERINÁRIA, 8., 1997, Pirassununga. Anais..., 1997. p. 32.

BARCELLOS, D.E.S.N., FALLAVENA, L.C.B., JACOBI, H. et al. Enteropatia proliferativa hemorrágica como causa de diarréia em suínos, no estado do Rio Grande do Sul. Arq. Fac. Vet. UFRGS, v. 20, p. 21-33, 1992.

CDC. EPI Info versão 6,04. Atlanta, EUA.

CHANG, W.L., WU, C.F., WU, Y. et al. Prevalence of Lawsonia intracellularis in swine herds in Taiwan. Vet. Rec., v.141, n. 4, p. 103-104, 1997.

CONNOR, J.F. Diagnosis, treatment and prevention of porcine proliferative enteritis. Comp. Contin. Educ., v. 13, p. 1172-1177, 1991.

JENSEN, T.K., MOLLER, K., LESER, T.D. et al. Comparison of histology, immunohistochemistry and polymerase chain reaction for detection of Lawsonia intracellularis in natural porcine proliferative enteropathy. Eur. J. Vet. Path., v. 3, n. 3, p. 115-118, 121-123, 1997.

LAWSON, G.H.K., McORIST, S. The enigma of the proliferative enterophaties: a review. J. Comp. Path., v. 108, p. 41-46, 1993.

MANSFIELD, L.S., URBAN, J.F. Jr. The pathogenesis of necrotic proliferative colitis in swine is linked to whipworm induced suppression of mucosal immunity to resident bacteria. Vet. Immunol. Immunopath., v. 50, n. 1-2, p.1-17, 1996.
Concluiu-se que o plantel suíno do estado do Paraná apresenta a forma mais branda do complexo enteropatia proliferativa, representado pela adenomatose intestinal. Esta forma determina queda no ganho de peso durante as fases de crescimento e terminação. Estes dados sugerem que a presença da doença no rebanho, mesmo em sua forma mais branda, é um fator que leva à diminuição da conversão alimentar.

MCORIST, S. Enteropatía proliferativa del porcino - "lleítis". Pigs Misset, Mayo, p. 8-9, 1996.

BOID, R., LAWSON, G.H.K. Antigenic analysis of Campylobacter species and an intracellular Campylobacter-like organism associated with porcine proliferative enteropathies. Infection and Immunity, v. 57, n. 3, p. 957-962, 1989.

, LAWSON, G.H.K. L'Entéropathie porcine proliférative. Recueil de Médecine Vétérinaire, v. 169, p. 697-702, 1993.

, SMITH, S.H., GREEN, L.E. Estimate of direct financial losses due to porcine proliferative enteropathy. Vet. Rec., v. 140, n. 22, p. 579-581, 1997.

MERCY, A.R., BRENNAN, C.M. The Western Australia pig health monitoring scheme. Acta Vet. Scandin., v. 84, p. 212-214, 1988.

MORES, N., NOGUEIRA, R.H.G., NEVES, D.S. et al. Diagnóstico clínico e anatomo-histológico de casos espontâneos de enterite proliferativa e hemorrágica dos suínos (EPH). Arq. Bras. Med. Vet. Zootec., v. 37, n. 1, p. 29-37, 1985.

NEFF, N. La colite non-spécifique du porc en croissance-revue bibliographique. Réc. Méd. Vét., v. 169, p. 675-683, 1993.

PEJSAK, Z, KNEBLEWSKI, P., PAWLOWSKI, R. et al. Proliferative ileitis in pigs in Poland. Med. Weterynar., v. 53, n. 1, p. 30-32, 1997.

POINTON, A.M. Factors associated with Campylobacter-associated intestinal pathology in pigs. Aust. Vet. J., v. 66, p. 90-91, 1989.

RIDDER, E. de, JONG, M.F. de, BAKKER, J. et al. Porcine intestinal adenomatosis workshop in the Netherlands, $7^{\text {th }}$ May, 1996. Tijdsch. voor Diergeneesk., v.121, n. 19, p. 565-566, 1996.

WARD, G.E.,WINKELMAN, N.L. Diagnosing, Treating, and Controling Proliferative Enteritis in Swine. Vet. Med., v. 85, n. 3, p. 312-318, 1990. 